\title{
Homograft aortic valve replacement: seven years' experience with antibiotic-treated valves
}

\author{
S K KHANNA, J K ROSS, AND J L MONRO \\ From the Department of Cardiac Surgery, Wessex Cardiac Centre, Southampton
}

ABSTRACT One hundred and sixty-five patients had their aortic valve replaced with an antibiotic sterilised homograft. In all cases, a two-layered freehand technique of valve implantation wa\$ used. Tailoring (narrowing) of the annulus was required in 29 cases, and an aortic root gusset. was used to enlarge the non-coronary sinus in 68 cases. There was an early mortality of $1.8 \% \omega^{\circ}$ and late mortality of $2.4 \%$. The actuarial survival rate was $95 \%$ at a maximum follow-up of seven years. The incidence of valvar regurgitation (early diastolic murmur) was $11.5 \%$ up to six months after operation and an additional $7 \cdot 2 \%$ subsequent to this. Overall, it was trivial in $10.3 \%$, mild in $7.8 \%$, and moderate in $0.6 \%$. Most valve regurgitation was non-progressive and actuarial analysis showed $74 \%$ regurgitation-free valves at the end of seven years. The age of the0 donor and the valve storage time showed some relationship to valve deterioration. Specia $\vec{I}$ attention has been paid to the control of hypertension to prevent accelerated graft degenerationo The results suggest that this has been successful. Anticoagulant therapy was not used ant thromboembolism has not been seen in patients undergoing isolated aortic valve replacement. There was one case of miliary tuberculosis after homograft valve replacement but no pyogeni or fungal endocarditis occurred. No haemolysis, calcification, or valvar stenosis were observed This series, followed for a maximum of seven years, shows excellent sustained valve performanç and a very low incidence of important postoperative regurgitation, with $91.8 \%$ of the survivor symptom-free.

After two decades of aortic valve surgery, controversy still exists over the choice of prosthetıc or biological valve substitute. While the former may have complications of thromboembolism, haemolysis, long-term anticoagulation, transaortic gradient in a small aortic root, and sudden death from valve dysfunction, the latter may have complications related to tissue failure and postoperative regurgitation. The problem of tissue failure in homograft valves was more evident when the valves were chemically sterilised, ${ }^{12}$ and is of less significance with valves sterilised by antibiotic solution. ${ }^{13-5}$

In the present series, with minor variations, there has been complete uniformity of valve preparation using antibiotic sterilisation and preservation in antibiotic/nutrient medium. Furthermore, all the valves have been replaced by two of us (JKR and JLM), which must also tend to eliminate variability when assessing results.

Address for reprint requests: Mr JL Monro, Consultant Cardiac Surgeon, Southampton Western Hospital, Oakley Road, Southampton SO9 4WQ.

\section{Patients and methods}

From October 1972 to September 1979, 749 aortie valve replacements were undertaken at th Wessex Cardiac Centre, Southampton. In $16 \$$ patients, aortic homograft valves were used. Most of them belonged to the middle age group, with male predominance (table 1). The youngest patient who received a homograft valve was 10 years old and the oldest was 75 years of age.

There were 58 patients with aortic stenosis, $3 \pi$ with regurgitation, and 70 with a mixed lesion

Table 1 Age and sex distribution of 165 patients (October 1972 to September 1979)

\begin{tabular}{|c|c|c|}
\hline Male $=106$ & Female $=59$ & $\mathbf{M}: \mathbf{F}=1 \cdot 7: 1$ \\
\hline $\begin{array}{l}\text { Age } \\
10-30 \text { years } \\
31-45 \text { years } \\
46-60 \text { years } \\
61-75 \text { years }\end{array}$ & & $\begin{array}{l}\text { Number } \\
12 \\
43 \\
71 \\
39\end{array}$ \\
\hline
\end{tabular}

Youngest patient $=10$ years Oldest patient $=75$ years 
In the group with regurgitation, two patients had mulfunctioning prosthetic valves and one had a leaking homograft valve, implanted elsewhere six years earlier. Two others had a palliative aortic valvotomy in childhood. In 17 patients associated mitral valve lesions were also treated and three had simultaneous saphenous vein bypass grafting. Associated non-cardiac lesions of importance include six cases of duodenal ulcer, two of hiatus hernia with reflux oesophagitis, and 14 cases of controlled systemic hypertension.

Shortness of breath was the most common presenting symptom with the majority of patients in grade II and III of the New York Heart Association (NYHA) classification (75.7\%). Angina of effort, syncope, and a history of left ventricular failure were present in $44.8 \%, 27.8 \%$, and $14.5 \%$ of patients respectively. There were 32 patients in functional class $I$ but they had either angina or effort syncope, and these symptoms were considered more critical than dyspnoea. Though duration of illness was very variable, the majority $(73.3 \%)$ had symptoms for less than two years.

The ECG showed evidence of left ventricular hypertrophy in $75.1 \%$ and a strain pattern in $57 \cdot 2 \%$. There were 12 patients with atrial fibrillation, five with left and three with right bundle branch block. In addition to routine investigations, electrocardiography, and chest X-ray, virtually all the patients had haemodynamic and cineangiocardiographic studies before operation. Our present policy is to perform coronary arteriography routinely in the preoperative investigation of patients with aortic valve disease. Earlier, this was confined to those with angina and, earlier still, it was only done occasionally. Patients shown to have coronary artery disease were generally not regarded as suitable candidates for homografts. This was, in part, related to trying to keep the period of cardiopulmonary bypass as short as possible and partly to anxiety about the efficacy of coronary perfusion. Both considerations are modified by the use of cardioplegia, but we would probably still prefer to use a prosthetic or xenograft valve in patients requiring multiple coronary grafts in addition to aortic valve replacement.

HOMOGRAFT VALVE COLLECTION AND PRESERVATION Unsterile donor hearts were collected within 72 hours of death from people between the ages of 14 and 50 years. The valves were dissected, examined, and measured in a clean laboratory. They were then sterilised and preserved in antibiotic/nutrient solution. The latter was prepared by mixing $66.5 \mathrm{ml}$ of nutrient medium and $33.5 \mathrm{ml}$ of antibiotic solution (table 2) and the valves were kept in this solution, initially for 24 hours at room temperature, and then at $4^{\circ} \mathrm{C}$ in a refrigerator after sending small aortic pieces for culture. After bacteriological clearance, the valves were usually kept for use for approximately eight weeks before being discarded, but 26 valves were used after eight weeks had elapsed.

Table 2 Composition of nutrient medium and antibiotic mixture

Nutrient medium

Constituents

Quantity $(m l)$

Sterile distilled water

Medium 199 (bicarbonate free)

Preheated inactivated calf serum no 1

Sodium bicarbonate $(4.4 \%)$

$10 \cdot 0$

$8 \cdot 0$

$5 \cdot \mathrm{C}$

$100 \cdot 0$

Antibiotic mixture

\begin{tabular}{lcc} 
Constituents & Amount & $\begin{array}{c}\text { Quantity } \\
(\mathrm{ml})\end{array}$ \\
\hline Nystatin & & 10.0 \\
Methicillin & $250000 \mathrm{U}$ & 1.4 \\
Erythromycin & $1000 \mathrm{mg}$ & 12.0 \\
Gentamicin & $600 \mathrm{mg}$ & 10.0 \\
Streptomycin & $400 \mathrm{mg}$ & 0.1 \\
& $20000 \mathrm{U}$ & 33.5
\end{tabular}

OPERATIVE TECHNIQUE

All the patients were operated on with a standard anaesthetic technique ${ }^{7}$ under conventional cardiopulmonary bypass with a bloodless prime. In the majority of cases, the aortic valve replacement was performed using continuous coronary perfusion with a beating heart, but in the last 32 cases, cold cardioplegic arrest with pericardial cooling was used.

In all cases, through a long, oblique aortotomy, the valve was assessed (table 3 ) and excised. The aortic annulus was then measured and an appropriate sized homograft was selected. The method of valve insertion used by both surgeons was essentially that described by Barratt-Boyes, ${ }^{8}$ and

Table 3 Aortic valve pathology

\begin{tabular}{lclc}
\hline Valve tvpe & Number & Cusp changes & Number \\
\hline Unicuspid & 2 & Calcification & 114 \\
Bicuspid & 67 & Thickened cusps & 33 \\
Tricuspid & 93 & Fenestration & 9 \\
Quadricuspid & 1 & Floppy (prolapsed) & 6 \\
Prosthetic valves & 2 & Thin attenuated & 2 \\
& & Healed bacterial & 3 \\
& & Endocarditis & \\
\hline
\end{tabular}


involved freehand suture of the valve in two layers. Table 4 refers to the differences in technique of the two surgeons.

Table 4 Differences in surgical techniques

\begin{tabular}{|c|c|c|}
\hline Surgical technique & $J L M$ & $J K R$ \\
\hline $120^{\circ}$ valve rotation ${ }^{8}$ & Yes & No \\
\hline Suture material & 3/0 Silk & 4/0 Prolene \\
\hline Additional sub-commissural suture ${ }^{9}$ & Yes & No \\
\hline $\begin{array}{l}\text { Stay fixation of commissural strut } \\
\text { with aorta (outward stitch) }\end{array}$ & No & Yes \\
\hline Aortic root tailoring & $7 \cdot 5 \%$ & $22 \cdot 3 \%$ \\
\hline Gusset to enlarge non-coronary sinus & $1.8 \%$ & $59 \cdot 8 \%$ \\
\hline
\end{tabular}

\section{Results}

\section{HOSPITAL AND EARLY MORTALITY}

There were three deaths $(1.8 \%)$ within 30 days of operation (table 5). There was no significant difference in early mortality between single and multiple valve procedures, coronary perfusion, and cardioplegia, or between the two surgeons involved.

Table 5 Mortality

\begin{tabular}{ll}
\hline Early Deaths ( $\leqslant 30$ days) $=3(1 \cdot 8 \%)$ & \\
\hline $\begin{array}{l}\text { Cause of Death } \\
1 \quad \text { Left coronary ostial stenosis } \\
\quad \text { Inadequate coronary perfusion) }\end{array}$ & $\begin{array}{l}\text { Days after operation } \\
\text { Intra-operative }\end{array}$ \\
$2 \quad \begin{array}{c}\text { Middle cerebral artery thrombosis } \\
\text { (Extensive cerebral infarction) }\end{array}$ & 12 \\
$3 \quad \begin{array}{c}\text { Sudden aortic rupture } \\
\text { (Associated Fragilitas ossium) }\end{array}$ & 14 \\
\hline
\end{tabular}

\begin{tabular}{ll}
\hline Late Deaths $=4(2 \cdot 4 \%)$ & \\
\hline Cause of Death & Months after operation \\
$1 \quad$ Pulmonary embolism & 2 \\
2 Miliary tuberculosis & 12 \\
$3 \quad$ Left ventricular failure & 12 \\
$4 \quad$ With arrhythmias) & \\
\hline
\end{tabular}

\section{HOSPITAL MORBIDITY}

The postoperative complications seen in this series included atrial arrhythmias (42), ventricular arrhythmias (10), bradycardia (three), temporary complete heart block (three), left ventricular failure with pulmonary oedema (one), and myocardial infarction (one), but none was directly related to the use of a homograft valve.

\section{LATE MORTALITY}

There were four late deaths $(2 \cdot 4 \%)$ in a follow-up of six months to seven years (table 5). These were caused by pulmonary embolism (one), miliary tuberculosis (one), and left ventricular failure (two). The latter two cases each had a grade II/ IV early diastolic murmur noted within a few months of surgery and restudy in both revealed insignificant aortic regurgitation with poor left ventricular function. Actuarial analysis of patient survival (using the method described by Anderson et $a l^{10}$ ) at the end of seven years was $95 \%$ and is shown in fig 1.

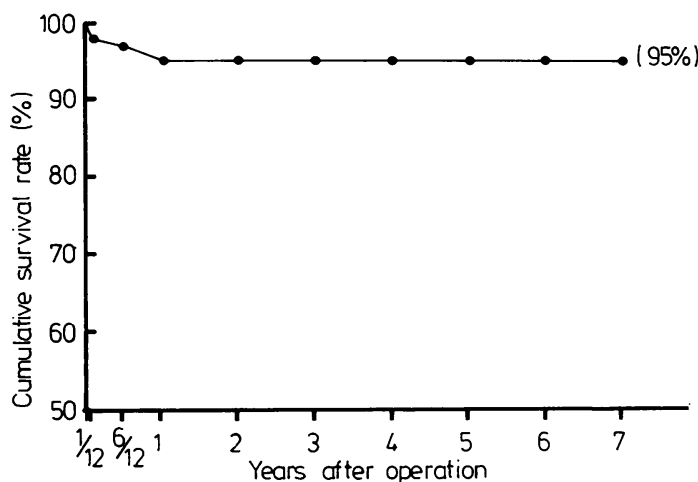

Fig 1 Actuarial analysis of survival after homograft replacement of the aortic valve.

\section{LATE MORBIDITY}

Various valve-related problems, appearing during follow-up, are shown in table 6.

Table 6 Valve-related late complications

\begin{tabular}{ll}
\hline Complication & Number \\
\hline Valve regurgitation & 31 \\
$\quad$ Trivial 17 & \\
Mild 13 & \\
Moderate 1 & 3 \\
Cerebral embolism (minor) & 1 \\
Heart block (tenth month) & 1 \\
Cusp rupture (forty-sixth month) & 1 \\
Endocarditis (miliary tuberculosis) & 0 \\
Valve stenosis & 0 \\
Leaflet calcification & \\
\hline
\end{tabular}

Postoperative aortic regurgitation

Based on the appearance of an early diastolic mut- N mur in the aortic area, pulse pressure, and clinical $N_{\omega}$ presentation, postoperative regurgitation was graded as trivial, mild, moderate, or severe. ${ }^{11}$ In the majority of those with regurgitation, it was either trivial or mild (fig 2 ) and was usually nonprogressive. Figure 3 shows the actuarial curve $\frac{7}{3}$ relating to the regurgitation-free period after $\frac{0}{\mathbb{D}}$ operation. In one patient $(0.6 \%)$, moderate re- $\stackrel{\odot}{\Phi}$ gurgitation occurred suddenly four years after $\stackrel{\mathbb{Q}}{2}$ operation and, at reoperation, proved to be the result of the rupture of one cusp. In $11.5 \%$ of $\Omega$ 


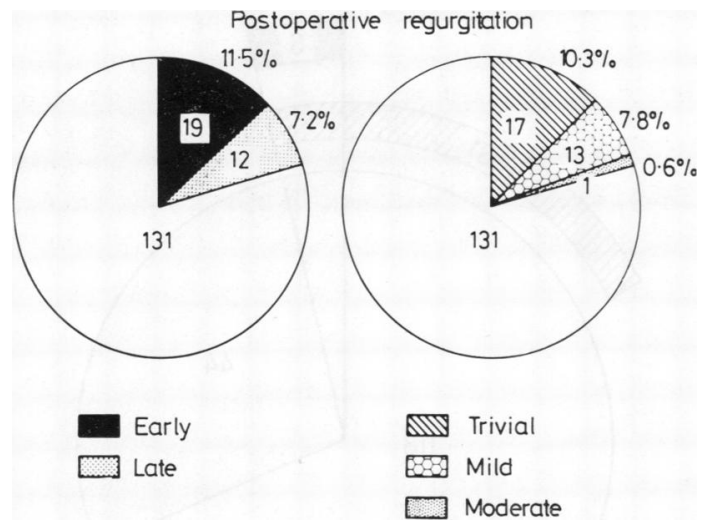

Fig 2 Incidence of postoperative aortic regurgitation in 162 survivors (131 patients had no regurgitation detected after operation).

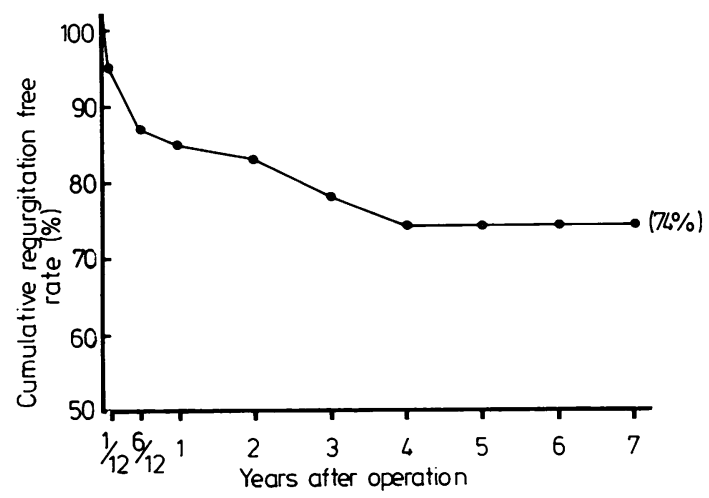

Fig 3 Actuarial curve relating to regurgitation-free interval after homograft aortic valve replacement.

cases, the regurgitant murmur was detected either in the immediate postoperative period or at the time of the first outpatient visit after operation and this was assumed to be caused by valve malposition.

Aortic root tailoring ${ }^{8}$ Nineteen patients were found to have aortic regurgitant murmurs immediately or soon after operation. The only significant factor here is whether or not the aortic root was reduced in size to accept a smaller homograft. Thus 12 out of $133(9.0 \%)$ without root tailoring were found to have early regurgitant murmurs, whereas seven out of $29(24 \cdot 1 \%)$ of those whose aortic roots were tailored, regardless of the technique used, showed early aortic regurgitation (fig 4).

Cardioplegia The use of cardioplegia reduced average implantation time from 127 minutes to about 110 minutes and the incidence of regurgita-

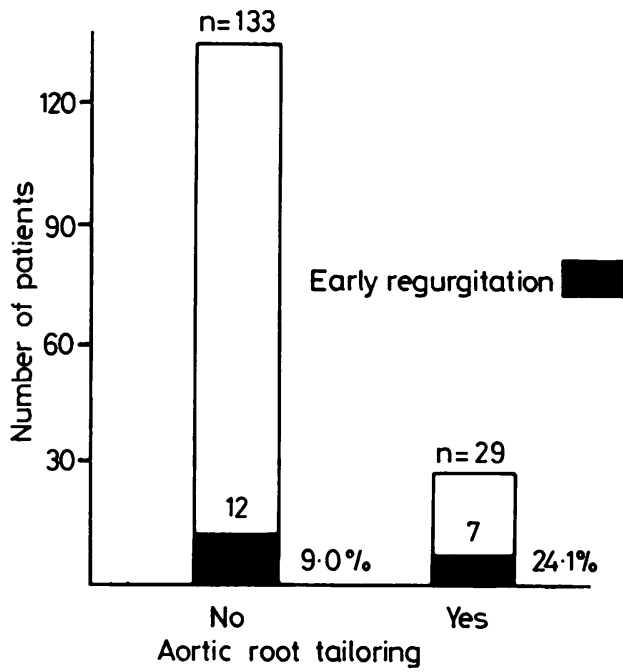

Fig 4 There is a positive correlation between the incidence of early postoperative regurgitation and aortic root tailoring.

tion was less $(12.5 \%)$ than in the non-cardioplegia group $(20 \cdot 3 \%)$.

Donor valves and regurgitation The incidence of regurgitation in this series was not related to donor valve size, death/collection interval, or blood group incompatibility (when this was known), but it was significantly higher when the age of the donors exceeded 45 years. There was also a direct relationship between the incidence of regurgitation and the length of time the valve had been kept before use (fig 5).

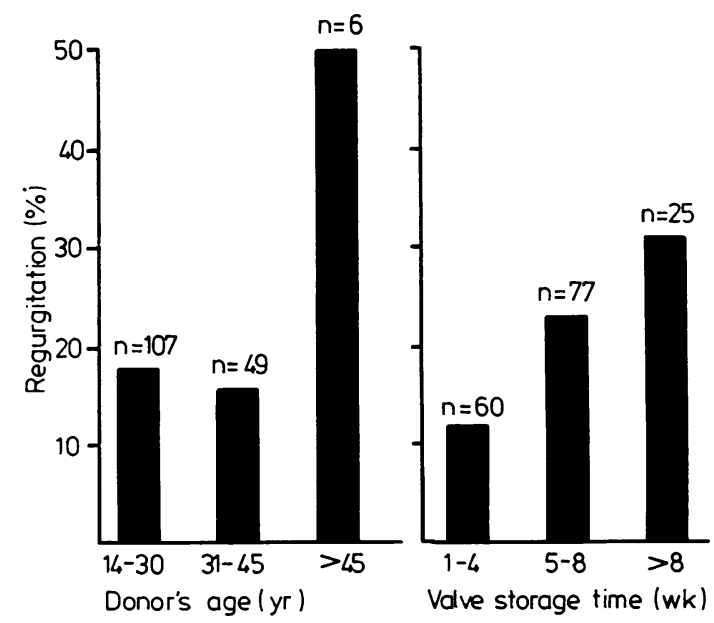

Fig 5 Incidence of homograft valve regurgitation increased with donor age and valve storage time. 
Aortic valve disease and regurgitation There was no relationship between the presence of preoperative regurgitation and postoperative aortic regurgitation.

Hypertension and regurgitation After operation, 44 patients $(26 \cdot 6 \%)$ were noted to have hypertension, but only six of them had some evidence of regurgitation (fig 6). Preoperative assessment of these hypertensive patients had revealed a diastolic pressure of more than $90 \mathrm{mmHg}$ in 14 cases, but there were 20 other patients $(12 \cdot 1 \%)$ with significant aortic regurgitation who had a widened pulse pressure $(>70 \mathrm{mmHg})$ and systolic hypertension. These patients were all found to be hypertensive in the early postoperative period and it may be postulated that their hypertension had been masked by their aortic valve disease. If these patients are excluded, only $10(7.6 \%)$ previously normotensive patients became hypertensive during the period covered by this review.

\section{Embolism}

After isolated homograft aortic valve replacement, patients were not anticoagulated and no systemic embolism was detected in this group. Transient minor embolic phenomena were observed in three patients $(1.8 \%)$, who had associated atrial fibrillation or mitral valve disease, after which they were anticoagulated.

\section{Valve failure}

There was only one case of cusp rupture demanding re-operation. This occurred after four years in a hypertensive patient who was on continuous cortisone therapy for rheumatoid arthritis. His cusp rupture was sudden and the valve was not regurgitant before this event. The homograft was replaced with a prosthetic valve.

Stenosis of the homograft valve did not occur in this series.

\section{Heart block}

One patient developed complete heart block 10 months after homograft valve replacement, and required a permanent pacemaker. This patient had calcium extending into the ventricular septum and required temporary pacing for a few hours after operation, but had been discharged in normal sinus rhythm.

\section{Endocarditis}

One patient developed generalised miliary tuberculosis eight months after operation, which originated from a cold abscess in relation to the donor valve. After this experience, streptomycin
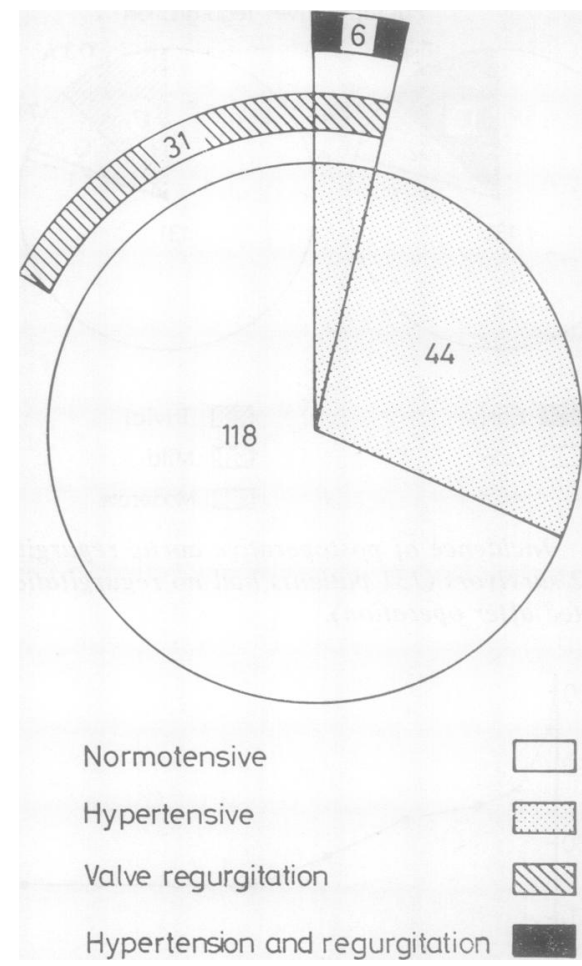

Fig 6 No difference in postoperative homograft valve regurgitation was observed in normotensive and controlled hypertensive patients.

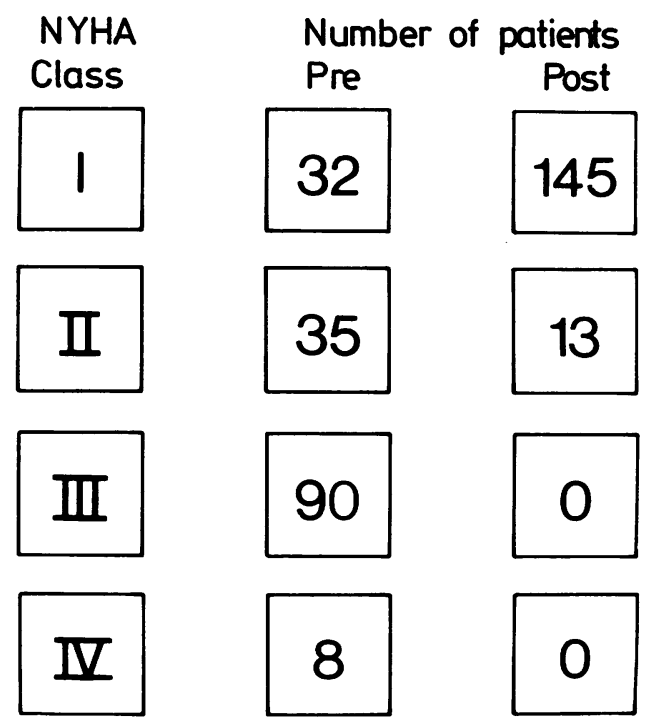

Fig 7 Preoperative (pre) and postoperative (post) frequency distribution of patients by New York Heart Association (NYHA) classification. 
was added to the antibiotic sterilising mixture. Pyogenic or fungal endocarditis was not seen.

\section{Clinical state}

All the survivors were seen at regular intervals and $91.8 \%$ of them were asymptomatic and in functional class I (fig 7). The remainder (8.2\%) had only minor symptoms.

\section{Discussion}

The homograft aortic valve has the advantage of natural design, normal flow pattern, and low antigenicity, without the complications of thromboembolism and haemolysis. Moreover, it is possible to implant it in its natural subcoronary position with a freehand technique without incorporating any prosthetic material or a stent. It is of particular value when the aortic root is small. Valve placement requires more operative time, which may in turn produce anxiety about myocardial protection, particularly in elderly patients, and those with multivalvular or associated coronary artery disease. That this is a risk factor is suggested by the higher mortality rate in such patients in another series. ${ }^{4}$ The high selectivity of the present series is evident as homografts were used in only $22 \%$ of all aortic valve replacements during the time under review. Factors favouring the use of a homograft valve included a history of gastrointestinal bleeding, intended childbearing, youth, the presence of a small aortic root, and the anticipation of difficult anticoagulation control. Applying these criteria, aortic valve replacement using homograft valves has given excellent results, with an operative mortality of $1.8 \%$ and an actuarial survival rate of $95 \%$ at seven years.
The appearance of valvar regurgitation has frequently been reported after homograft aortic valve replacement (table 7) and there was an 18.7\% incidence in this study. One encouraging point was that in the majority it was either trivial or mild and was usually non-progressive to the limit of the period of follow-up. In a significant number of cases $(11.5 \%)$ it was noted in the early postoperative period and was probably related to valve malposition. A normal-looking valve may not remain competent if tested at higher pressures, ${ }^{15}$ and as many as $20 \%$ of human valves may be found to have mild central regurgitation when tested in vitro at systemic pressures. ${ }^{16}$ This may explain some early postoperative regurgitant murmurs. When aortic root tailoring ${ }^{8}$ proved necessary, the incidence of the early appearance of diastolic murmurs was increased $(24.1 \%)$ in comparison with non-tailored roots $(9 \cdot 0 \%)$. A similar observation was made by Barratt-Boyes. ${ }^{6}$

The late appearance of regurgitant murmurs in $7 \cdot 2 \%$ of survivors may be related to nontechnical factors, notably donor age and valve storage time. In this study, a direct relationship was observed between the incidence of regurgitation and the duration of valve storage time. This is very similar to the observations made by Bodnar et al. ${ }^{17}$ Hypertension is a known factor, as pointed out by Layton et al. ${ }^{18}$ Special attention was paid to the blood pressure in the follow-up period, and active treatment was given to the hypertensive patients.

Immunological injury had been considered another important factor contributing to valve failure by Buck et al, ${ }^{19}$ who suggested inserting homograft valves into patients with the same blood group as the donor. We found no relationship

Table 7 Homograft aortic valve replacement (review of results)

\begin{tabular}{|c|c|c|c|c|c|c|c|c|c|c|}
\hline \multirow[t]{2}{*}{ Reference } & \multirow[t]{2}{*}{ Period } & \multirow{2}{*}{$\begin{array}{l}\text { No of } \\
\text { Patients }\end{array}$} & \multicolumn{2}{|c|}{ Mortality (\%) } & \multicolumn{2}{|c|}{ Regurgitation (\%) } & \multirow{2}{*}{$\begin{array}{l}\text { Valve } \\
\text { Failure } \\
(\%)\end{array}$} & \multirow[t]{2}{*}{ Re-operation } & \multirow[t]{2}{*}{ Embolism } & \multirow{2}{*}{$\begin{array}{l}\text { Endocarditis } \\
(\%)\end{array}$} \\
\hline & & & Early & Late & $\begin{array}{l}\text { Trivial } \\
\text { or mild }\end{array}$ & $\begin{array}{l}\text { Moderate } \\
\text { or severe }\end{array}$ & & & & \\
\hline Moore et $a l^{2}$ & $\begin{array}{l}1963-67 \\
1968-73\end{array}$ & $\begin{array}{l}156 \\
118\end{array}$ & $\begin{array}{r}21 \cdot 3 \\
3 \cdot 9\end{array}$ & $\begin{array}{r}13 \cdot 5 \\
2 \cdot 9\end{array}$ & $\begin{array}{l}60 \\
18\end{array}$ & - & $\begin{array}{r}20 \\
4\end{array}$ & - & - & - \\
\hline $\begin{array}{l}\text { Barratt-Boyes } \\
\text { et } \text { al }^{4}\end{array}$ & $1968-71$ & 121 & $5 \cdot 7$ & $27 \cdot 0$ & 43 & 9 & - & 9 & $\stackrel{2}{(1.65 \%)}$ & - \\
\hline Thompson et $a l^{5}$ & $1969-78$ & 411 & $3 \cdot 9$ & $10 \cdot 5$ & 21 & $6 \cdot 8$ & $5 \cdot 9$ & $\begin{array}{r}14 \\
3.4 \%\end{array}$ & Nil & $1 \cdot 7$ \\
\hline $\begin{array}{c}\text { Anderson and } \\
\text { Hancock }\end{array}$ & $1967-71$ & 114 & $8 \cdot 8$ & $\begin{array}{l}5 \cdot 8 \\
\text { (First year) }\end{array}$ & - & 10 & - & 20 & $\begin{array}{l}5 \% \\
(\mathrm{MV} / \mathrm{AF}) *\end{array}$ & $4 \cdot 3$ \\
\hline $\begin{array}{l}\text { Karp and } \\
\text { Kirklin }^{13}\end{array}$ & $1967-72$ & 307 & $4 \cdot 2$ & $4 \cdot 8$ & 36 & 12 & - & $6 \cdot 1 \%$ & $3 \%$ & - \\
\hline Soorae et al ${ }^{14}$ & $1967-77$ & 38 & $8 \cdot 0$ & $8 \cdot 0$ & 46 & - & - & 15 & - & - \\
\hline Precent series & $1972-79$ & 165 & $1 \cdot 8$ & $2 \cdot 4$ & $18 \cdot 7$ & 0.6 & 0.6 & $0.6 \%$ & $\begin{array}{l}1.8 \% \\
(\mathrm{MV} / \mathrm{AF})^{*}\end{array}$ & 0.6 \\
\hline
\end{tabular}

*In cases with associated mitral valve disease or atrial fibrillation only. 
between $\mathrm{ABO}$ compatibility and valve regurgitation in our series; a similar observation was made by Balch and Karp. ${ }^{20}$

In this series, the incidence of cusp rupture was $0.6 \%$ suggesting that treatment with antibiotic/ nutrient medium is less damaging to valve tissue than chemical sterilisation. This low incidence of late cusp rupture may be partly because there is more in-growth of host tissue and less macrophage activity in antibiotic-treated valves ${ }^{21}$

In the early part of this series, one patient died of generalised miliary tuberculosis eight months after operation and this infection originated from the donor valve. A similar occurrence has been reported by Anyanwu et al, ${ }^{22}$ and, since that time, we have routinely added streptomycin to the sterilising and preservative solution. There has been no pyogenic or fungal endocarditis and no other case of tuberculous infection.

Valvar stenosis or calcification, though reported by others, ${ }^{523}$ was never a problem in our patients, and this may reflect the fact that the donor valves were always from relatively young people (less than 50 years of age). Thromboembolism was a rarity, minor when it did occur and found only in patients having associated mitral valve disease and atrial fibrillation.

In conclusion, review of our patients, with a maximum follow-up of seven years, emphasises the excellent performance of the antibiotic-treated homograft aortic valve, which, although it may not be suitable for all aortic valve replacements, is still a valuable valve substitute and compares favourably with other biological and prosthetic valves.

We would like to thank our cardiological colleagues, Dr Alan Johnson and Dr Neville Conway, whose cases are here reported, Miss Y Siebert, Homograft Technician to the Unit, for her scrupulous preparation of the aortic valve homografts described in this communication, and the many pathologists who have helped us with valve collection.

\section{References}

1 Gavin JB, Herdson PB, Barratt-Boyes BG. The pathology of chemically sterilised human heart valve allografts. Pathology 1972; 4:175-83.

2 Moore CH, Martelli V, Al-Janabi N, Ross DN. Analysis of homograft valve failure in 311 patients up to 10 years. Ann Thorac Surg 1975; 20:274-81.

3 Angell WW, Angell JD, Sywak A. Selection of tissue or prosthetic valve. (A five-year prospec- time randomized comparison.) J Thorac Cardiovasc Surg 1977; 73:43-53.

4 Barratt-Boyes BG, Roche AHG, Whitlock RML. 믐 Six year review of the results of freehand aortic $\frac{C}{\partial}$ valve replacement using an antibiotic sterilised $\overline{\bar{\sigma}}$ homograft valve. Circulation 1977; 55:353-61.

5 Thompson $R$, Yacoub $M$, Ahmed $M$, Somer- $\varrho$ ville W, Towers $M$. The use of "fresh" unstented œ homograft valves for replacement of the aortic $\overrightarrow{0}$ root. (Analysis of 8 years' experience). J Thorac Cardiovasc Surg 1980; 79:896-903.

6 Barratt-Boyes BG. Cardiothoracic surgery in the Antipodes. J Thorac Cardiovasc Surg 1979; 78: $\underset{\times}{\vec{x}}$ 804-22.

7 Manners JM. Anaesthesia for cardiac surgery. In: Norman J, Whitwam JG eds. Topical reviews in anaesthesia. Bristol: John Wright 1980; 179- ట్ర 260.

8 Barratt-Boyes BG. Method for preparing and in- 음 serting a homograft valve. Br J Surg 1965; 52: 二 847-56.

9 Gonzalez-Lavin L, Barratt-Boyes BG. Surgical considerations in the treatment of ventricular $\overrightarrow{0}$ septal defect associated with aortic valvular in- $\stackrel{\infty}{\rightarrow}$ competence. J Thorac Cardiovasc Surg 1969; 57: 422-30.

10 Anderson RP, Boncheck LI, Grunkemeier GL, Lambert LE, Starr A. Analysis and presentation $\overline{0}$ of surgical results by actuarial methods. J Surg 을 Res 1974; 16:224-30.

11 Barratt-Boyes BG, Lowe JB, Cole DS, Kelly DT. Homograft valve replacement for aortic valve disease. Thorax 1965; 20:495-504.

12 Anderson ET, Hancock EW. Longterm followup of aortic valve replacement with the fresh aortic homograft. J Thorac Cardiovasc Surg 1976; 72: 150-6.

13 Karp RB, Kirklin JW, Kouchoukos NT, Pacifio AD. Comparison of three devices to replace the aortic valve. Circulation 1974; suppl II, 49:163-9.

14 Soorae S, O'Kane H, Molloy PJ, Cleland J. Comparative analysis of isolated aortic valve replacement with fascia lata and homograft valves. $J \subseteq$ Thorac Cardiovasc Surg 1978; 76:46-55.

15 Khanna SK, Talwar JR, Gopinath N. Assessment of incompetence in canine aortic and pulmonary valve grafts and comparison of some methods of $\sigma$ valve preservation. J Cardiovasc Surg 1977; 18: 505-8.

16 Khanna SK, Gopinath N, Talwar JR, Chandra J. Morphological and functional study of human aortic valves. Ind J Surg 1976; 38:485-9.

17 Bodnar E, Wain WH. Martelli V, Ross DN. Longterm performance of 580 homograft and autograft valves used for aortic valve replacement. Thorac Cardiovasc Surg 1979; 27:31-8.

18 Layton C, Brigden W, McDonald L, Monro J, McDonald A, Weaver J. Systemic hypertension after homograft aortic valvar replacement. A cause of late homograft failure. Lancet 1973; 2: 1343-7. 
19 Buch WS, Kosek JC, Angell WW. The role of rejection and mechanical trauma on valve graft viability. J Thorac Cardiovasc Surg 1971; 62:696706.

20 Balch CM, Karp RB. Blood group compatibility and aortic valve allotransplantation in man. $J$ Thorac Cardiovasc Surg 1975; 70:256-9.

21 Gavin JB, Herdson PB, Monro JL, Barratt-
Boyes BG. Pathology of antibiotic-treated human heart valve allografts. Thorax 1973; 28:473-81.

22 Anyanwu $\mathrm{CH}$, Nassau E, Yacoub MH. Miliary tuberculosis following homograft valve replacement. Thorax 1976; 31:101-6.

23 Kosinski EJ, Cohn PF, Grossman W, Cohn LH. Severe stenosis occurring in antibiotic sterilised homograft valves. Br Heart J 1978; 40:194-7. 